\section{ATP metabolizing enzymes ENPP1, 2 and 3 are localized in sensory neurons of rat dorsal root ganglion}

\author{
Kentaro Nishida,* Yuka Nomura, \\ Kanako Kawamori, Akihiro Ohishi, \\ Kazuki Nagasawa
}

Department of Environmental Biochemistry, Kyoto Pharmaceutical University, Yamashina-ku, Kyoto, Japan

*Present address: Faculty of Pharmaceutical Sciences, Setsunan University, Osaka, Japan

\section{Abstract}

In dorsal root ganglion (DRG) neurons, ATP is an important neurotransmitter in nociceptive signaling through $\mathrm{P} 2$ receptors (P2Rs) such as $\mathrm{P} 2 \mathrm{X} 2 / 3 \mathrm{R}$, and adenosine is also involved in anti-nociceptive signaling through adenosine A1R. Thus, the clearance system for adenine nucleotide/nucleoside plays a critical role in regulation of nociceptive signaling, but there is little information on it, especially ectoenzyme expression profiles in DRG. In this study, we examined expression and localization of ectonucleotide pyrophosphatase/phosphodiesterases (ENPPs), by which ATP is metabolized to AMP, in rat DRG. The mRNA expression levels of ENPP2 were greater than those of ENPP1 and ENPP3 in rat DRGs. On immunohistochemical analysis, ENPP1, 2 and 3 were found in soma of DRG neurons. Immunopositive rate of ENPP3 was greater than that of ENPP1 and ENPP2 in all DRG neurons. ENPP3, as compared with ENPP1 and ENPP2, was expressed mainly by isolectin B4-positive cells, and slightly by neurofilament 200-positive ones. In this way, the expression profile of ENPP1, 2 and 3 was different in DRGs, and they were mainly expressed in small/medium-sized DRG neurons. Moreover, ENPP1-, 2- and 3-immunoreactivities were colocalized with P2X2R, $\mathrm{P} 2 \mathrm{X} 3 \mathrm{R}$ and prostatic acid phosphatase (PAP), as an ectoenzyme for metabolism from AMP to adenosine. Additionally, PAP-immunoreactivity was colocalized with equilibrative nucleoside transporter (ENT) 1, as an adenosine uptake system. These results suggest that the clearance system consisted of ENPPs, PAP and
ENT1 plays an important role in regulation of nociceptive signaling in sensory neurons.

\section{Introduction}

ATP plays an important role in cell to cell communication in the peripheral nervous system. In dorsal root ganglion (DRG), ATP is released from DRG neurons through stimuli such as noradrenaline, ${ }^{1}$ and is involved in nociceptive signaling by acting through $\mathrm{P} 2$ receptors such as $\mathrm{P} 2 \mathrm{X} 2 / 3 \mathrm{R} .{ }^{2,3}$ ATP released from DRG neurons is metabolized by ectonucleotidases, which produce nucleotides/nucleosides such as ADP, AMP, adenosine, etc., and extracellular adenosine is taken up by a clearance system such as equilibrative nucleoside transporter (ENT), ${ }^{1}$ which contributes to maintenance of their concentrations in physiological ranges. ${ }^{4}$ Ectonucleotidases play an important role in control of nociceptive signaling via nucleotides/nucleosides. ${ }^{5} \quad$ Additionally, Zylka et al. ${ }^{6}$ and Sowa et al. ${ }^{7}$ reported that prostatic acid phosphatase (PAP) and ecto5'-nucleotidase (NT5E, CD73), which were expressed by DRG neurons, dephosphorylate AMP to adenosine, and adenosine is involved in anti-nociceptive signaling via activation of its A1 receptor (A1R) expressed by DRG neurons. ${ }^{8}$ These findings indicate that ectonucleotidases play a critical role in regulation of nociceptive signaling in DRG. As for ATP-metabolizing ectonucleotidases, nucleoside triphosphate diphosphohydrolase (NTPDase) 1, 2, 3 and 8, and ecto-nucleotide pyrophosphatase/ phosphodiesterase (ENPP) 1, 2 and 3 have been identified in mammals. ${ }^{5}$ NTPDase 1, 2, 3 and 8 are expressed in a variety of tissues (e.g., epidermal dendritic cells, blood vessels, neurons and liver, respectively). ${ }^{9-12}$ Vongtau et al. reported that among NTPDase1, 2, 3 and 8, NTPDase 3 was localized in soma of mouse DRG neurons. ${ }^{13}$ However, NTPDase3 knockout mice did not show nociceptive behavior compared with wild-type mice, ${ }^{14}$ suggesting that other ectonucleotidases such as ENPPs might contribute to ATP-metabolism on DRG neurons. ENPP1, 2 and 3 dephosphorylate ATP to AMP and pyrophosphate, and are expressed on epithelial surfaces such as lung epithelia, liver epithelia, kidney epithelia and intestinal epithelia, ${ }^{15-18}$ but the distributions of ENPP1, 2 and 3 in DRG neurons are unknown.

In this study, to reveal the distributions of ectonucleotidases and transport system for regulation of extracellular levels of ATP
Correspondence: Kazuki Nagasawa, Department of Environmental Biochemistry, Kyoto Pharmaceutical University, 5 Nakauchi-cho, Misasagi, Yamashina-ku, Kyoto 607-8414, Japan.

Tel. +81.75.595-4648 - Fax: +81.75.5954756. E-mail: nagasawa@mb.kyoto-phu.ac.jp

Key words: Ecto-nucleotide pyrophosphatase/phosphodiesterase; dorsal root ganglion; ATP, ectoenzyme; clearance system; sensory neuron.

Acknowledgments: We thank Mr. N. J. Halewood for his helpful advice regarding the manuscript.

Funding: Parts of this study were financially supported by a Grant-in-Aid for Young Scientists (B) (\#22790134) from the Ministry of Education, Culture, Sports, Science and Technology, Japan, and grants from the Kyoto Pharmaceutical University Fund for the Promotion of Scientific Research and the Nakatomi Foundation, and a grant from the Ministry of Education, Culture, Sports, Science and Technology of Japan (MEXT)Supported Program for the Strategic Research Foundation at Private Universities, 20132017.

Conflict of interest: The authors declare that no competing interests exist.

Received for publication: 28 November 2017 Accepted for publication: 16 March 2018.

This work is licensed under a Creative Commons Attribution-NonCommercial 4.0 International License (CC BY-NC 4.0)

(C) Copyright K. Nishida et al., 2018

Licensee PAGEPress, Italy

European Journal of Histochemistry 2018; 62:2877 doi:10.4081/ejh.2018.2877

and its metabolites in sensory neurons, we examined the expression profiles of ENPP1, 2 and 3, NTPDases, PAP and ENT1 in rat DRG neurons.

\section{Materials and Methods}

\section{Materials}

Normal donkey serum and normal goat serum were purchased from Abcam (Tokyo, Japan). Bovine serum albumin (BSA) was purchased from Sigma-Aldrich (St. Louis, MO, USA). All other chemicals were obtained from Wako Pure Chemical Ind. (Osaka, Japan), except where otherwise noted. 
Table 1. Primers for real-time PCR.

\begin{tabular}{|c|c|c|c|c|}
\hline Gene & & Primer sequences & Product size & Accession no. \\
\hline Ntpdasel & $\begin{array}{l}\text { Forward } \\
\text { Reverse }\end{array}$ & $\begin{array}{l}\text { 5'-AGGACATTCAGGTTTCAAGTGGTG-3“ } \\
\text { 5'-AGTGCCATAGAGTTCGCTTACATTC-3' }\end{array}$ & 95 bp & NM_022587 \\
\hline Ntpdase2 & $\begin{array}{l}\text { Forward } \\
\text { Reverse }\end{array}$ & $\begin{array}{l}\text { 5'-AGACAGACATGCTAGCACAC-3' } \\
\text { 5'-AGCACCACGGAAGTCAAAGG-3' }\end{array}$ & $145 \mathrm{bp}$ & NM_172030.1 \\
\hline Ntpdase3 & $\begin{array}{l}\text { Forward } \\
\text { Reverse }\end{array}$ & $\begin{array}{l}\text { 5'-TTGTGTCGGAAGAGAAGATGGAC-3' } \\
\text { 5'-ACTGGAAACTGTGCGTGTAGAGAG-3' }\end{array}$ & $96 \mathrm{bp}$ & NM_178106 \\
\hline Ntpdase8 & $\begin{array}{l}\text { Forward } \\
\text { Reverse }\end{array}$ & $\begin{array}{l}\text { 5'-TCACCATGCTCATCCTCATCC-3 } \\
\text { 5'-TCCTGTGTCCTTCTCCTTGTTTG-3' }\end{array}$ & 146 bp & NM_001033565 \\
\hline Enpp1 & $\begin{array}{l}\text { Forward } \\
\text { Reverse }\end{array}$ & $\begin{array}{l}\text { 5'-GAATGGCGTCAATGTTGTCAG-3' } \\
\text { 5'-GACTGCGGATGACTCTGGTG-3' }\end{array}$ & $118 \mathrm{bp}$ & NM_053535 \\
\hline Enpp2 & $\begin{array}{l}\text { Forward } \\
\text { Reverse }\end{array}$ & $\begin{array}{l}\text { 5'-CCACTACTACAGCATCATCACCAG-3' } \\
\text { 5'-GGATGAAGAAGACACAGAGAGG-3' }\end{array}$ & 118 bp & NM_057104 \\
\hline Enpp3 & $\begin{array}{l}\text { Forward } \\
\text { Reverse }\end{array}$ & $\begin{array}{l}\text { 5'-ACAACGGTTCTCACGGTAGCC-3' } \\
\text { 5'-GCGAGGCAGGAGCAGTTTAG-3' }\end{array}$ & $118 \mathrm{bp}$ & NM_019370 \\
\hline$A c t b$ & $\begin{array}{l}\text { Forward } \\
\text { Reverse }\end{array}$ & $\begin{array}{l}\text { 5'-TGACCCTGAAGTACCCCATTG-3' } \\
\text { 5'-TGTAGAAATGTGGTGCCAAATC-3' }\end{array}$ & 81 bp & NM_031144 \\
\hline
\end{tabular}

Table 2. Antibodies used for immunohistochemistry.

\begin{tabular}{|c|c|c|}
\hline Antigen & Primary antibodies & Secondary antibodies \\
\hline NTPDase2 & $\begin{array}{l}\text { Sheep anti-NTPDase2 Ab } \\
\text { (1:500; \#AF5797, R\&D SYSTEMS) }\end{array}$ & $\begin{array}{l}\text { Donkey anti-sheep IgG conjugated with Alexa Fluor }{ }^{\circledR} 594 \\
\left(1: 1000 ; \# A 11016 \text {, Life Technologies }{ }^{\mathrm{TM}}\right)\end{array}$ \\
\hline ENPP1 & $\begin{array}{l}\text { Rabbit anti-ENPP1 Ab } \\
(1: 100 ; \text { \#bs-1760R, Bioss) }\end{array}$ & $\begin{array}{l}\text { Donkey anti-rabbit IgG conjugated with Alexa Fluor }{ }^{\circledR} 488 \\
\text { (1:1000; \#A21206, Life Technologies }{ }^{\mathrm{TM}} \text { ) } \\
\text { Donkey anti-rabbit IgG conjugated with Alexa Fluor }{ }^{\circledR} 594 \\
\text { (1:1000; \#A21207, Life Technologies } \\
\text { Goat anti-rabbit IgG conjugated with Alexa Fluor }{ }^{\circledR} 546 \\
\text { (1:1000; \#A11010, Life Technologies }{ }^{\mathrm{TM}} \text { ) }\end{array}$ \\
\hline ENPP2 & $\begin{array}{l}\text { Rabbit anti-ENPP2 Ab } \\
\text { (1:100; \#LS-C37249, LifeSpan Bioscience) }\end{array}$ & $\begin{array}{l}\text { Donkey anti-rabbit IgG conjugated with Alexa Fluor }{ }^{\circledR} 488 \\
\left.\text { (1:1000; \#A21206, Life Technologies }{ }^{\mathrm{TM}}\right) \\
\text { Donkey anti-rabbit IgG conjugated with Alexa Fluor }{ }^{\circledR} 594 \\
\left.\text { (1:1000; \#A21207, Life Technologies }{ }^{\mathrm{TM}}\right) \\
\text { Goat anti-rabbit IgG conjugated with Alexa Fluor }{ }^{\circledR} 546 \\
\left(1: 1000 ; \# A 11010 \text {, Life Technologies }{ }^{\mathrm{TM}}\right)\end{array}$ \\
\hline ENPP3 & $\begin{array}{l}\text { Rabbit anti-ENPP3 Ab } \\
\text { (1:500; \#LS-A9843, MBL) }\end{array}$ & $\begin{array}{l}\text { Donkey anti-rabbit IgG conjugated with Alexa Fluor }{ }^{\circledR} 488 \\
\left.\text { (1:1000; \#A21206, Life Technologies }{ }^{\mathrm{TM}}\right) \\
\text { Donkey anti-rabbit IgG conjugated with Alexa Fluor }{ }^{\circledR} 594 \\
\text { (1:1000; \#A21207, Life Technologies } \\
\text { GM }) \\
\left(1: 1000 ; \# \text { \#A11010, Life Technologies }{ }^{\mathrm{TM}}\right)\end{array}$ \\
\hline GFAP & $\begin{array}{l}\text { Rabbit anti-GFAP Ab } \\
\text { (1:200; \#AB5804, Millipore) }\end{array}$ & $\begin{array}{l}\text { Donkey anti-rabbit IgG conjugated with Alexa Fluor }{ }^{\circledR} 488 \\
\left(1: 1000 ; \# \text { \#21206, Life Technologies }{ }^{\mathrm{TM}}\right)\end{array}$ \\
\hline NF200 & $\begin{array}{l}\text { Mouse anti-NF200 Ab } \\
\text { (1:500; \#N 0142, Sigma) }\end{array}$ & $\begin{array}{l}\text { Goat anti-mouse IgG conjugated with Alexa Fluor }{ }^{\circledR} 488 \\
\left(1: 1000 ; \# \text { Al1001, Life Technologies }{ }^{\mathrm{TM}}\right)\end{array}$ \\
\hline IB4 & $\begin{array}{l}\text { FITC-conjugated Isolectin B4 } \\
(10 \mu \mathrm{g} / \mathrm{mL} \text {, \#FL-1201; Vector Laboratories) }\end{array}$ & \\
\hline CGRP & $\begin{array}{l}\text { Mouse anti-CGRP Ab } \\
\text { (1:100; \#sc-57053, Santa Cruz) }\end{array}$ & $\begin{array}{l}\text { Goat anti-mouse IgG conjugated with Alexa Fluor }{ }^{\circledR} 488 \\
\text { (1:1000; \#A11001, Life Technologies }\end{array}$ \\
\hline PAP & $\begin{array}{l}\text { Chicken anti-PAP Ab } \\
\text { (1:100; \#PAP, Aves Labs) }\end{array}$ & $\begin{array}{l}\text { Goat anti-chicken IgY conjugated with FITC } \\
\text { (1:1000; \#F-1005, Aves Labs) }\end{array}$ \\
\hline $\mathrm{P} 2 \mathrm{X} 2 \mathrm{R}$ & $\begin{array}{l}\text { Guinea pig anti-P2X2 Ab } \\
\text { (1:100; \#GP14106, Neuromics Antibodies) }\end{array}$ & $\begin{array}{l}\text { Goat anti-guinea pig IgG conjugated with Alexa Fluor }{ }^{\circledR} 488 \\
\text { (1:1000; \#A11073, Life Technologies }\end{array}$ \\
\hline P2X3R & $\begin{array}{l}\text { Guinea pig anti-P2X3 Ab } \\
\text { (1:500; \#ab10267, Abcam) }\end{array}$ & $\begin{array}{l}\text { Goat anti-guinea pig IgG conjugated with Alexa Fluor }{ }^{\circledR} 488 \\
\text { (1:1000; \#A11073, Life Technologies }\end{array}$ \\
\hline ENT1 & $\begin{array}{l}\text { Rabbit anti-ENT1 Ab } \\
\text { (1:200; \#11337-1-AP, Proteintech) }\end{array}$ & $\begin{array}{l}\text { Goat anti-rabbit IgG conjugated with Alexa Fluor }{ }^{\circledR} 546 \\
\left(1: 1000 ; \# A 11010 \text {, Life Technologies }{ }^{\mathrm{TM}}\right)\end{array}$ \\
\hline
\end{tabular}




\section{Animals}

Male Sprague-Dawley rats $(190 \pm 10 \mathrm{~g}$; Japan SLC, Hamamatsu, Japan) were housed with food and water available ad libitum in a controlled environment with a $12 \mathrm{~h} / 12 \mathrm{~h} \mathrm{light/dark}$ cycle. These experiments were approved by the Experimental Animal Research Committee of Kyoto Pharmaceutical University. All animal experiments were performed according to the Guidelines for Animal Experimentation of Kyoto Pharmaceutical University.

\section{Total RNA extraction and real-time PCR}

Rats were perfused transcardially with saline under deep anesthesia (pentobarbital sodium, $25 \mathrm{mg} / \mathrm{kg}$, i.p.). Rat DRG tissues were isolated from lumbar 4-6, and then were treated with an RNAlater ${ }^{\circledR}$ solution (Sigma-Aldrich) at $-20^{\circ} \mathrm{C}$. Total RNA was extracted and reverse transcribed with a Gene Elute ${ }^{\mathrm{TM}}$ Mammalian Total RNA Miniprep Kit (Sigma-Aldrich) and a PrimeScript $^{\mathrm{TM}}$ RT reagent kit (TaKaRa, Shiga, Japan) according to the manufacturer's instruction manuals, respectively. Realtime PCR was performed with an ABI PRISM 7500 Real Time PCR System (Applied Biosystems) using SYBR Premix Ex Taq (TaKaRa). The primer sets are shown in Table 1. All reactions were confirmed not to be non-specific amplification by each dissociation curve. A negative control $\left(\mathrm{H}_{2} \mathrm{O}\right)$ without the template was included in all reactions.

\section{Antigen specificity of antibodies for immunohistochemistry}

The antigen specificity of antibodies for ENPP1, 2 and 3, and ENT1 was evaluated by means of an antibody adsorption test (Supplementary Figure 1). ${ }^{19}$ Primary antibodies were adsorbed with recombinant antigens for $1 \mathrm{~h}$ at room temperature at the antibody:antigen ratio of 1:3 for ENPP1, 2 and 3 (Supplementary Table 1), and then cryosections were treated with the adsorbed antibodies instead of primary antibodies, followed by incubation with the secondary antibodies. As for NTPDase2, we confirmed that the antibody used for the detection of it has specific immunoreactivity to rat DRGs by using Western blot analysis (Supplementary Method), and main protein band of NTPDase 2 was detected in the rat DRG within the range of $50-75 \mathrm{kDa}$ (Supplementary Figure 2).

\section{Immunohistochemistry}

Sprague-Dawley rats were perfused transcardially with $4 \%$ paraformaldehyde in Sorensen's phosphate-buffered saline (Sorensen's PBS; 19 mM NaH${ }_{2} \mathrm{PO}_{4}, 81 \mathrm{mM}$ $\mathrm{Na}_{2} \mathrm{HPO}_{4}, \mathrm{pH} 7.4$ ) containing $0.2 \%$ picric acid under deep anesthesia (pentobarbital sodium; Kyoritsu Seiyaku Co., Tokyo, Japan; $25 \mathrm{mg} / \mathrm{kg}$, i.p.). The isolated DRGs (L4-6) were sliced at $40 \mu \mathrm{m}$ thickness with a cryostat (CM1850; Leica, Wetzlar, Germany). Free-floating sections were washed with phosphate-buffered saline (PBS; $133 \mathrm{mM} \mathrm{NaCl}, 8.6 \mathrm{mM} \mathrm{K}_{2} \mathrm{HPO}_{4}, 1.5$ $\mathrm{mM} \mathrm{KH} \mathrm{PO}_{4}, \mathrm{pH}$ 7.6), and treated with blocking buffer (PBS containing 1\% donkey or goat serum, $0.3 \%$ Triton X-100, $0.3 \%$ BSA and $0.05 \%$ sodium azide), and then immunoreacted with the primary antibodies (Table 2) in blocking buffer for 3 days at $4^{\circ} \mathrm{C}$, followed by incubation for a day at $4^{\circ} \mathrm{C}$ with the secondary antibodies (Table 2) and $1 \mu \mathrm{g} / \mathrm{mL}$ Hoechst 33258 in the same buffer as that used for the primary antibodies. The blocking buffer used for immunohistochemistry of ENPP3, P2X2R, P2X3R and ENT1 was Can Get Signal ${ }^{\circledR}$ immunostain solution B (TOYOBO, Osaka, Japan). The free-floating sections were mounted on glass slides (Matsunami glass, Osaka, Japan) and dried out, and then enclosed using a Prolong Antifade Kit (Life Technologies, Tokyo, Japan). Photomicrographs were obtained under a confocal laser microscope (LSM510 META; Carl Zeiss, Oberkochen, Germany). For all immunostaining, a negative control was prepared by omitting the primary antibodies, and the reproducibility was confirmed using sections from 3 or 4 rats per immunostaining.

\section{Image analysis}

For quantitative analysis of ENPP1-, 2and 3-immunoreactivity, image quantification and processing were performed with Image J software (ver. $1.48 \mathrm{v}$; National Institutes of Health, Bethesda, MD, USA). The background signal for individual antibodies was determined from the corresponding negative control. The region of interest (ROI) feature of the Image J software was used to measure the cell area and fluorescence intensity. Area measurements were made by drawing the outlines of cell bodies. Cells were classified as immune-positive if
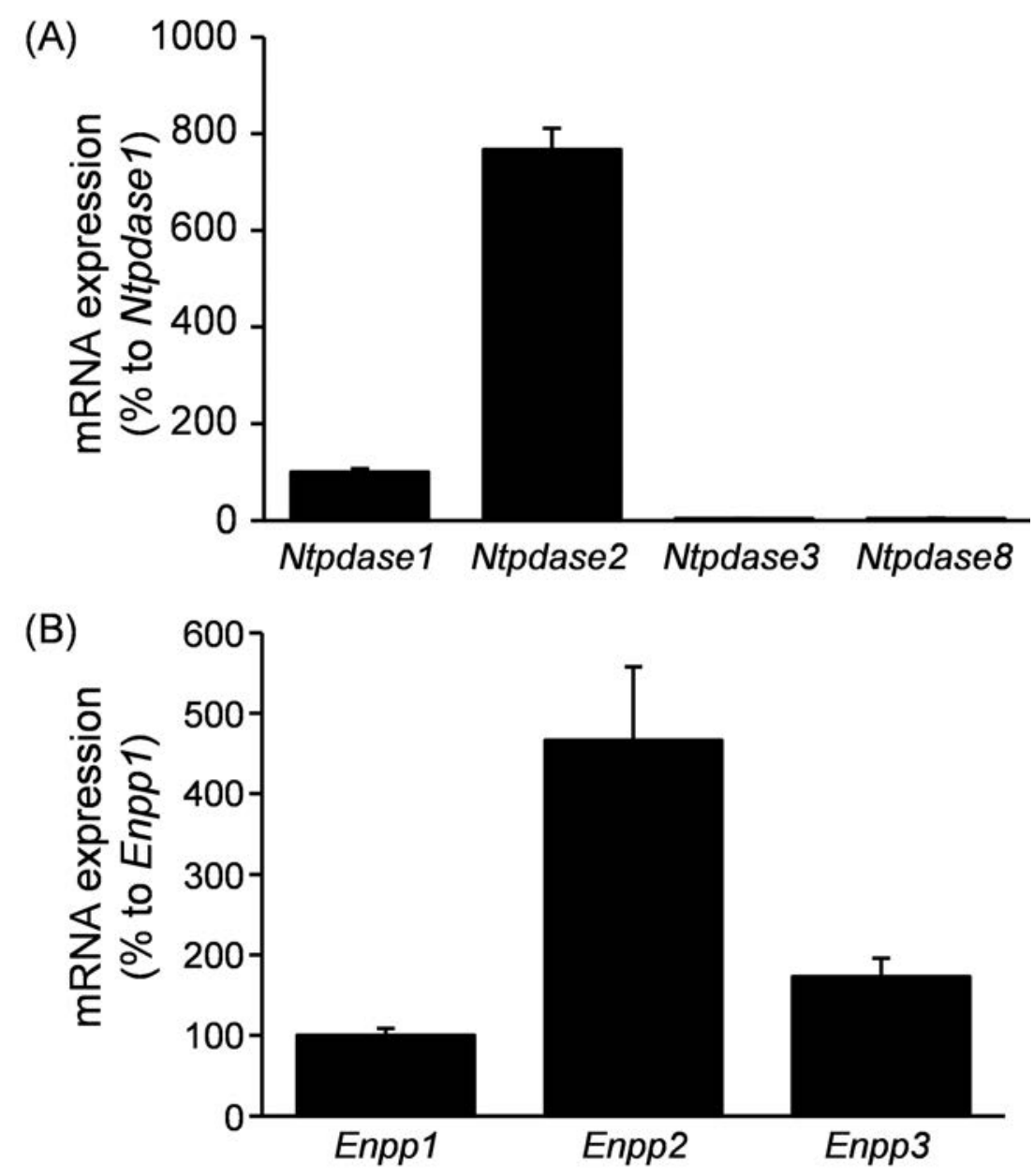

Figure 1. Expression of mRNA for NTPDases and ENPPs in rat DRG. mRNA expression of NTPDases (A) and ENPPs (B) in rat DRG was quantitatively analyzed by real-time PCR. The amount of mRNA was normalized by comparison with that of mRNA for NTPDase1 (A) or ENPP1 (B). Each bar represents the mean + SD $(N=3-7)$. 
their staining intensities were three times the standard deviation above the background excluding the nucleus. Furthermore, percentage of each marker-positive neuron number as to ENPP1-, 2- and 3-, PAP- and ENT1-positive neuron number was calculated.

\section{Statistical analysis}

All values are shown as means \pm SD. Comparisons between two or three groups were performed by means of paired $t$-test or one-way analysis of variance followed by Tukey-Kramer test, differences with a Pvalue of 0.05 or less being considered statistically significant.

\section{Results}

mRNA expression levels of NTPDases and ENPPs in rat DRG

On quantitative real-time PCR analyses, the mRNA expression levels of NTPDase2 and ENPP2 were apparently greater than those of NTPDase1, 3 and 8, and ENPP1 and 3, respectively, in rat DRGs (Figure 1). These results indicated that rat DRGs exhibited relatively high expression levels of NTPDase2 and ENPP2 mRNAs.

\section{Localization of NTPDase2, and ENPP1, 2 and 3 in rat DRGs}

On immunohistochemistry, NTPDase2immunoreactivity was primarily detected in the regions surrounding sensory neuronal soma, and was detected mainly in GFAPpositive satellite cells (Figure 2), indicating that NTPDase2 was localized mainly in satellite cells of rat DRGs, and there was no or negligible expression of it in DRG neurons.

As shown in Figure 3, the soma of the DRGs showed ENPP1-, 2- and 3- immunoreactivity, and on quantification, the immunopositive rate of ENPP3 in all DRG neurons $(54.8 \pm 18.4 \%)$ was significantly greater than that of ENPP1 and ENPP2, $25.4 \pm 11.3 \%$ and $26.6 \pm 11.4 \%$, respectively $(v s \%$ of ENPP3, $\mathrm{P}<0.05$, Tukey-Kramer test). Moreover, correlation of their fluorescent intensity with the cell body size of DRG neurons (Figure $3 \mathrm{D}-\mathrm{F}$ ) indicated that they tended to be expressed by small- to medium-sized DRG neurons. Following the report of Bergman and Ulfhake, ${ }^{20}$ cells with cell body areas of less than $750 \mu \mathrm{m}^{2}$, between 750 and $1750 \mu \mathrm{m}^{2}$,

Table 3. Immunopositive rates of IB4, CGRP, NF200, P2X2R, P2X3R and PAP in ENPP1-, 2- and 3-positive neurons.

\begin{tabular}{lllc}
\hline Marker & ENPP1 & ENPP2 & ENPP3 \\
IB441.9 \pm 6.6 & $41.5 \pm 13.2$ & $60.8 \pm 6.2$ & \\
CGRP & $29.7 \pm 16.5$ & $23.9 \pm 8.9$ & $27.4 \pm 10.1$ \\
\hline NF200 & $33.8 \pm 7.2$ & $13.1 \pm 8.0$ & $4.6 \pm 5.2$ \\
P2X2R & $87.1 \pm 7.6$ & $82.9 \pm 9.1$ & $77.8 \pm 10.5$ \\
\hline P2X3R & $83.9 \pm 11.5$ & $93.1 \pm 11.4$ & $82.6 \pm 10.0$ \\
PAP60.9 \pm 14.8 & $49.8 \pm 12.9$ & $54.6 \pm 6.4$ & \\
\hline
\end{tabular}

Each value was calculated based on the data shown in Figures 4-6 and means the percentage of each marker-positive neuron number as to ENPP1-, 2- and 3-positive neuron one. Each value represents the mean \pm SD $(n=3-5)$.

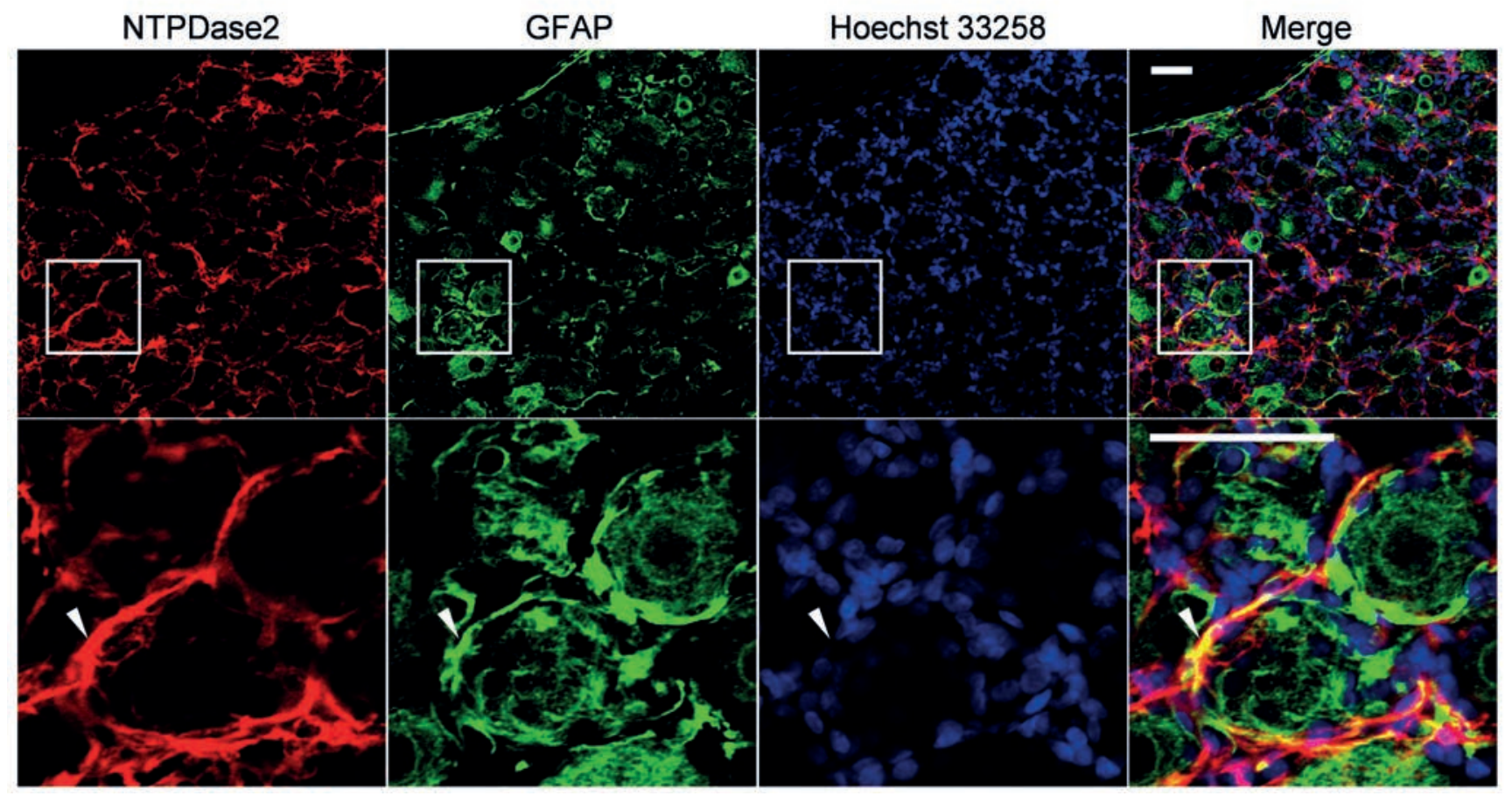

Figure 2. Immunohistochemical analysis of NTPDase2 in rat DRG. Immunostaining for NTPDase2 (red) with GFAP (green)-positive satellite cells and nucleus marker Hoechst 33258 (blue) was performed. Arrowheads indicate the colocalization of NTPDase2 and GFAP. The lower panel shows a magnified image of the square area in the upper panel. Representative images from three independent experiments are shown. Scale bar: $50 \mu \mathrm{m}$. 
(A)

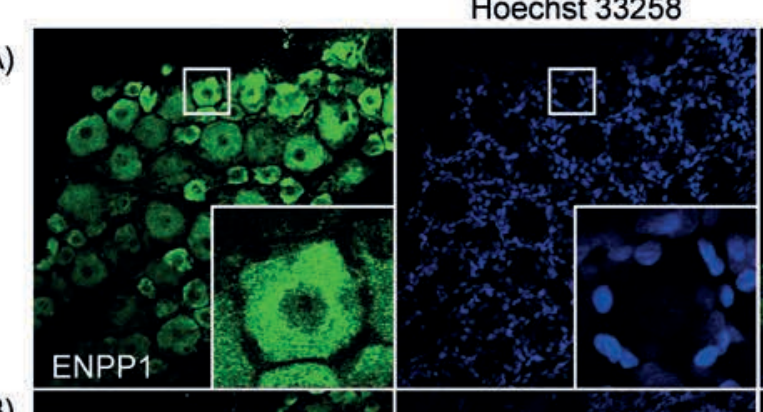

Hoechst 33258

(B)
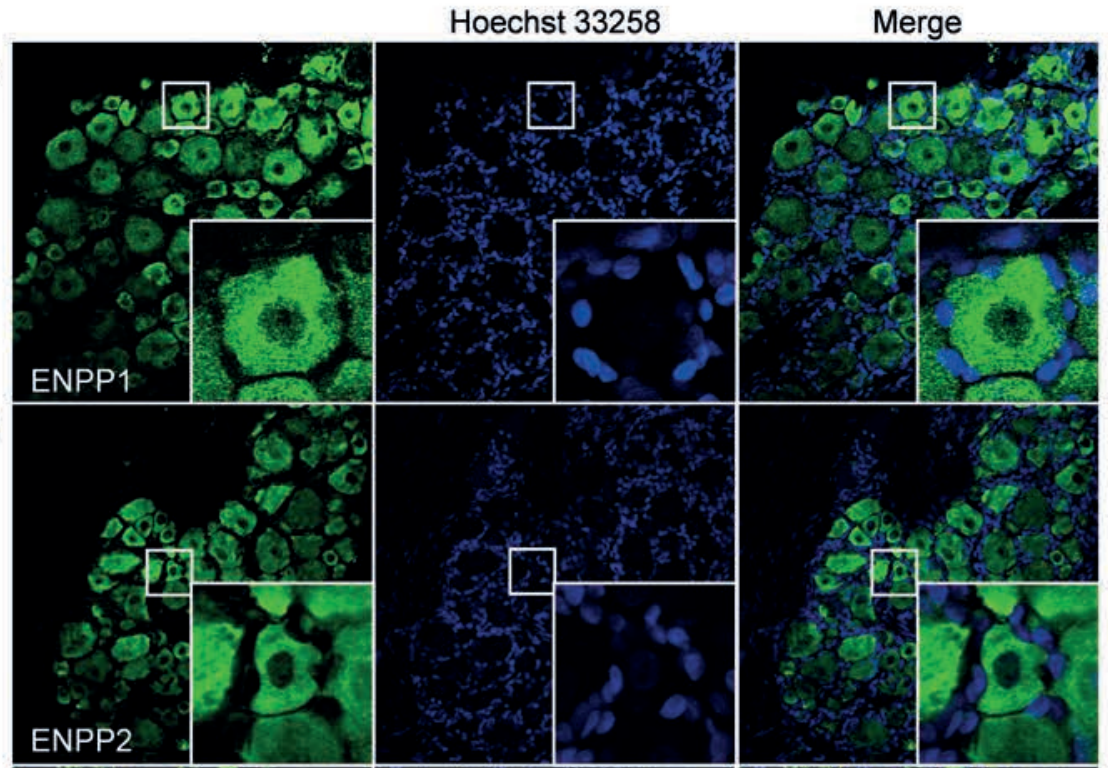

(C)
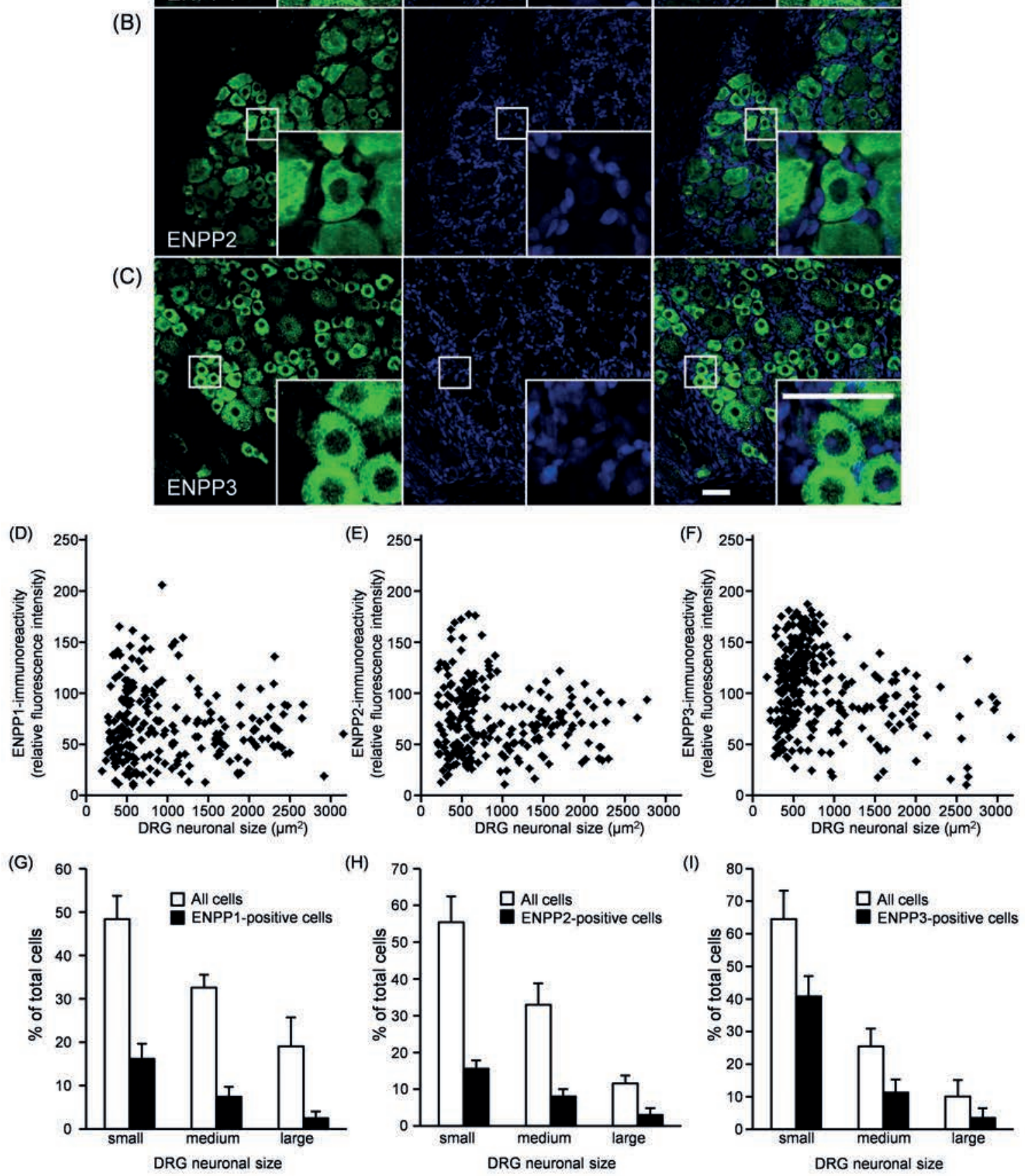

Figure 3. Immunohistochemical analysis of ENPP1, ENPP2 and ENPP3 in rat DRG. A-C) Representative images of ENPP1, ENPP2 and ENPP3 in rat DRG are shown $(n=4)$; nuclei were stained with Hoechst 33258; the insets show magnified images of the square areas; scale bar: $50 \mu \mathrm{m}$. D-F) Distribution of ENPP1-, ENPP2- and ENPP3-immunofluoresent intensity in the DRG neuronal cell body (soma) $v s$ cell size for all DRG neurons is shown in panels D, E and F, respectively. G-I) Size distribution histograms of ENPP1-, ENPP2- and ENPP3-positive DRG neurons, respectively. DRG neurons were classified as ENPP1-, ENPP2- or ENPP3-positive when the cytoplasmic intensity was three SDs above the background, divided into small- (less than $\left.750 \mu \mathrm{m}^{2}\right)$, medium- $\left(750-1750 \mu \mathrm{m}^{2}\right)$, and large- (larger than $\left.1750 \mu \mathrm{m}^{2}\right)$ DRG neurons. Each bar represents the mean + SD (n=4). 


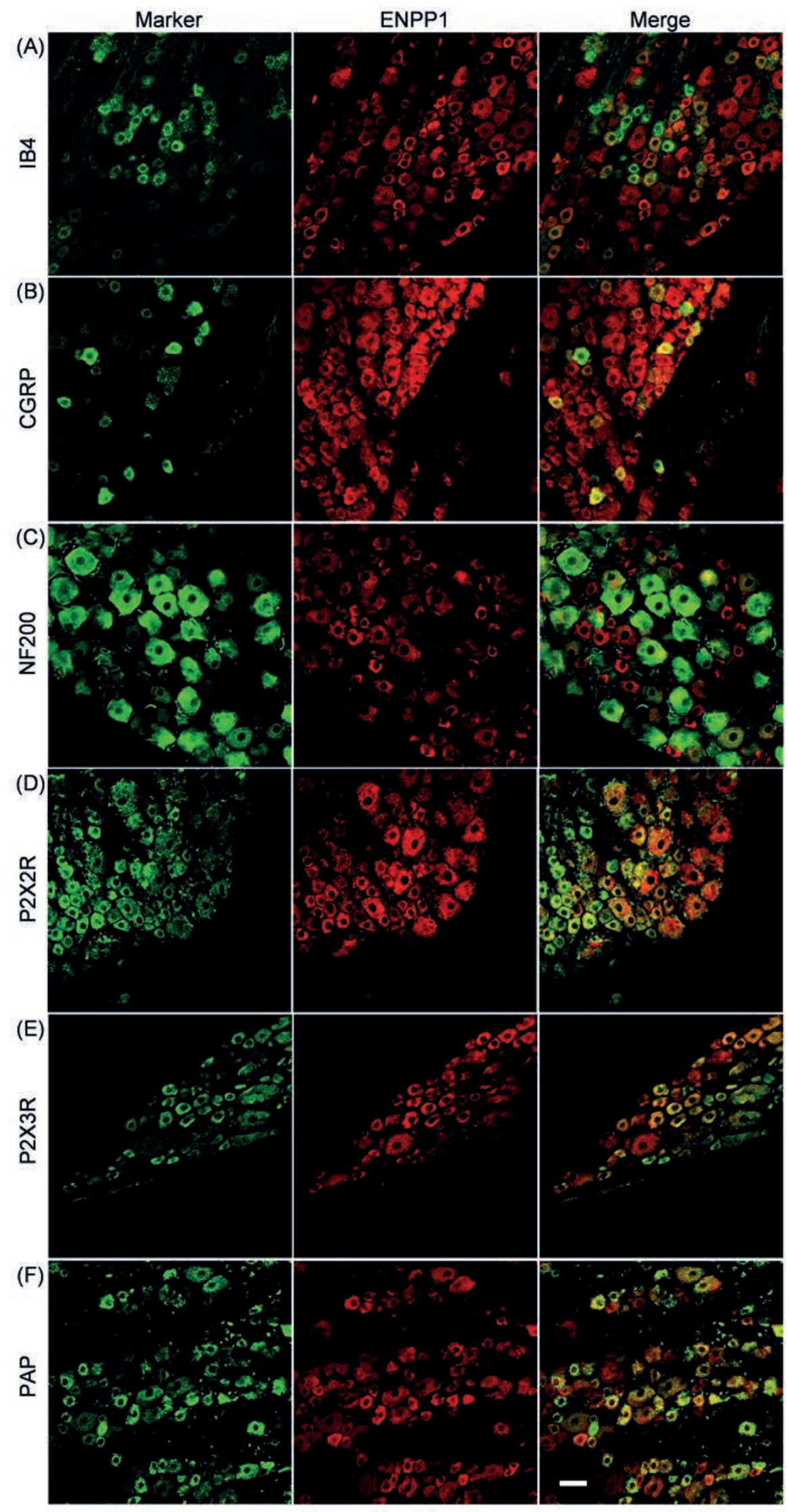

Figure 4. Distribution of ENPP1 in rat DRG neurons. Double-immunostaining for a neuronal marker (green) and ENPP1 (red) is shown. IB4 (A), CGRP (B), NF200 (C), P2X2R (D), P2X3R (E), and PAP (F) were used as neuronal markers. Representative images from three to four independent experiments are shown. Scale bar: $50 \mu \mathrm{m}$. 


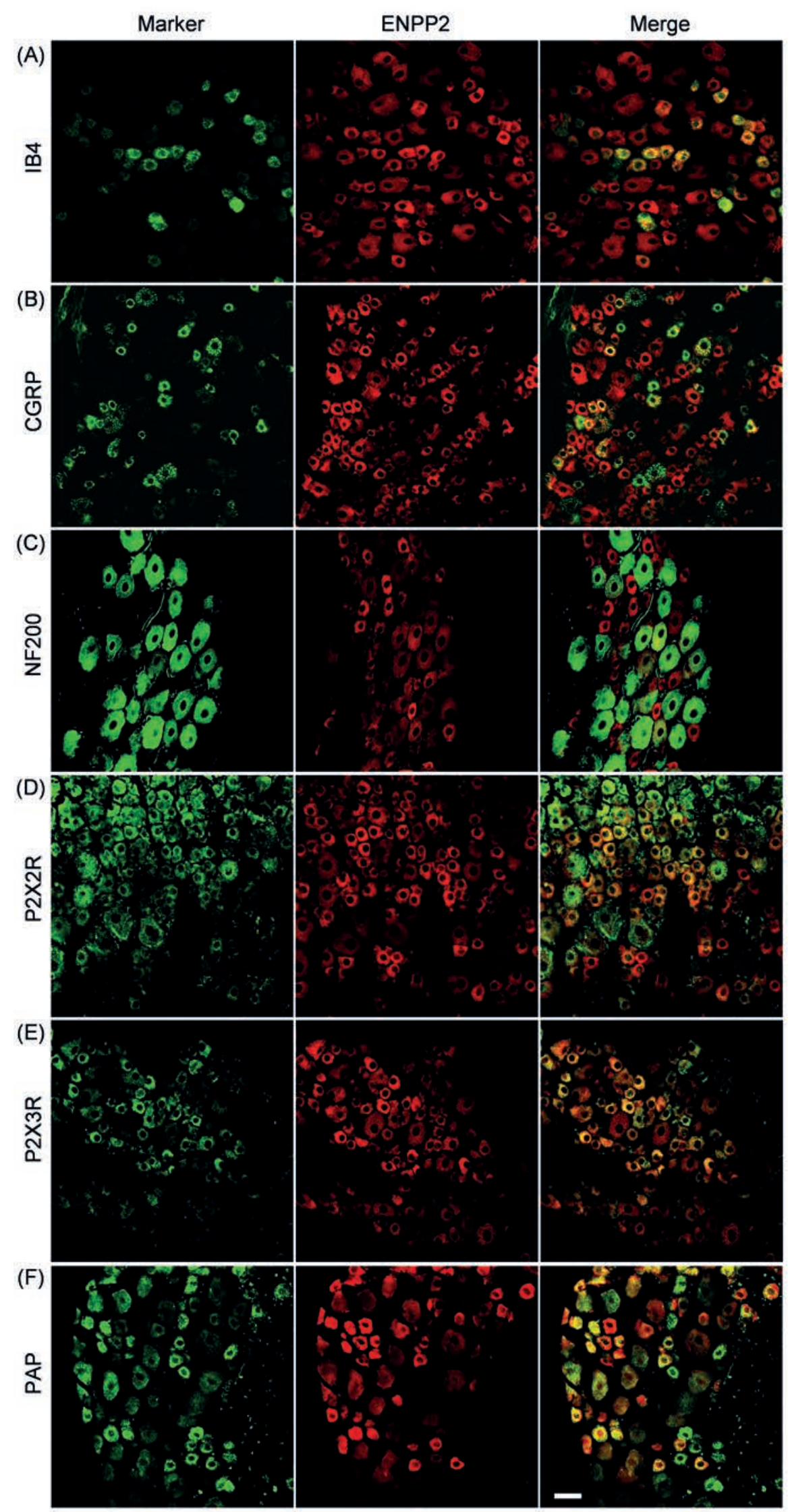

Figure 5. Distribution of ENPP2 in rat DRG neurons. Double-immunostaining for a neuronal marker (green) and ENPP2 (red) is shown. IB4 (A), CGRP (B), NF200 (C), P2X2R (D), P2X3R (E), and PAP (F) were used as neuronal markers. Representative images from four to five independent experiments are shown. Scale bar: $50 \mu \mathrm{m}$. 


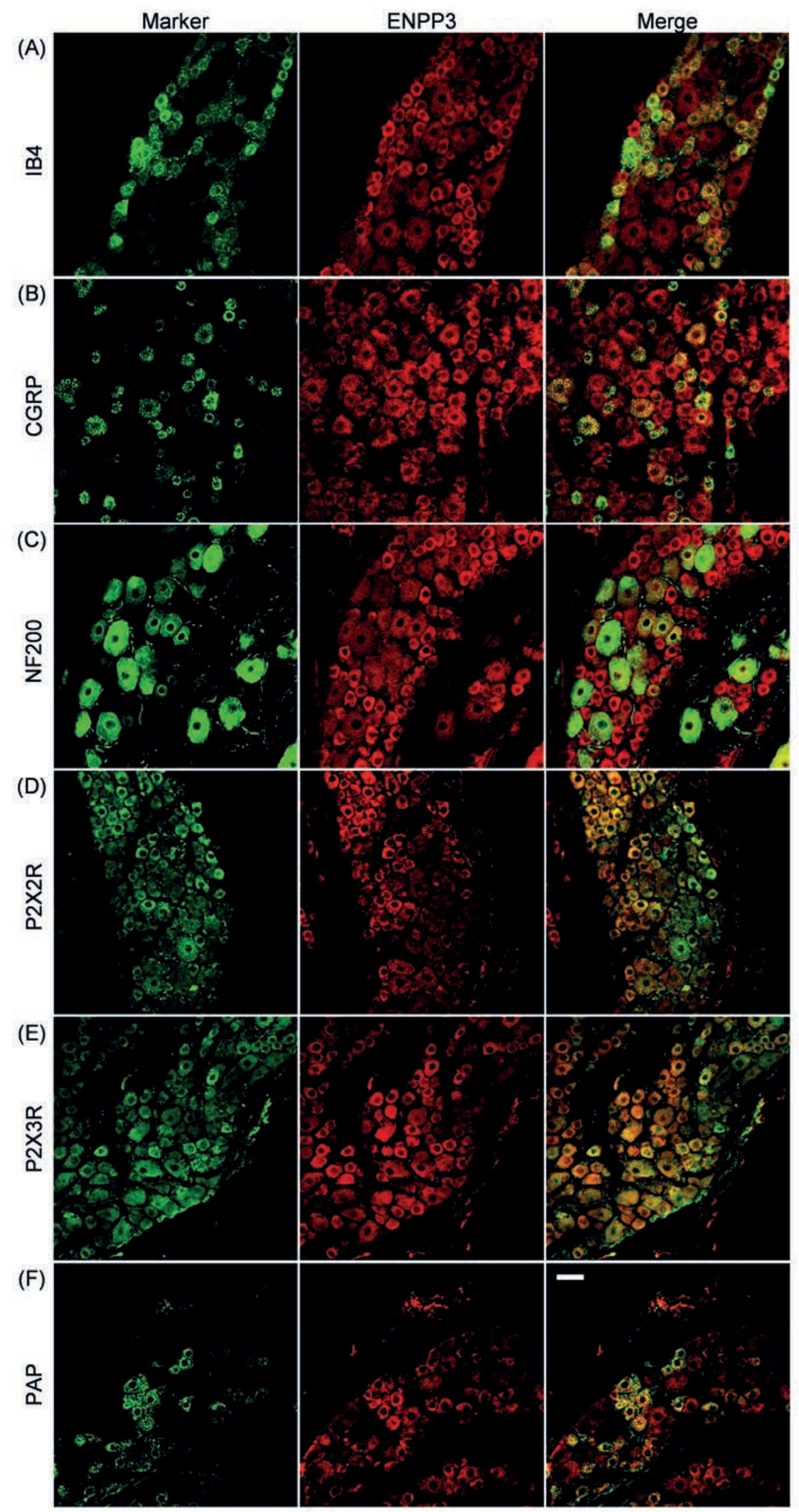

Figure 6. Distribution of ENPP3 in rat DRG neurons. Double-immunostaining for a neuronal marker (green) and ENPP3 (red) is shown. IB4 (A), CGRP (B), NF200 (C), P2X2R (D), P2X3R (E), and PAP (F) were used as neuronal markers. Representative images from three to four independent experiments are shown. Scale bar: $50 \mu \mathrm{m}$. 
and over $1750 \mu \mathrm{m}^{2}$ were defined as small-, medium-, and large-sized DRG neurons, respectively, and detailed expression profiles of ENPP1, 2 and 3 were examined. As shown in Figure 3 G-I, the expression levels of ENPP1, 2 and 3 were greater in the order of small->medium->large-sized neurons. Regarding neuronal cell types expressing ENPP1, 2 and 3, their immunoreactivities were found in IB4-positive nonpeptidergic and CGRP-positive peptidergic neurons, as small-sized neuronal markers (panels A and $\mathrm{B}$ of Figures 4-6). ${ }^{21,22}$ To show their distribution more clearly, the immunopositive rates of IB4 and CGRP were calculated. In fact, of the ENPP1-, 2- and 3-positive neurons, $41.9 \pm 6.6 \%, \quad 41.5 \pm 13.2 \%$ and $60.8 \pm 6.2 \%$, respectively, were IB4-positive ones, whereas $29.7 \pm 6.5 \%, 23.9 \pm 8.9 \%$ and $27.4 \pm 10.1 \%$, respectively, were CGRP-positive ones (Table 3). ENPP1-, 2- and 3immunoreactivities were detected in NF200-positive neurons, as medium- and large-sized neuronal markers (panel $\mathrm{C}$ of Figures 4-6), ${ }^{22,23}$ and their immunopositive rates of NF200 were calculated to be $33.8 \pm 7.2,13.1 \pm 8.0$ and $4.6 \pm 5.2 \%$, respectively (Table 3 ). To reveal coexpression of P2X2R and P2X3R, which are expressed by medium- and small/medium-sized neurons, respectively, ${ }^{24-26}$ and adenosine-generating enzymes such as PAP with ENPP1, 2 and 3, immunofluorescence double staining was carried out. As shown in panels D-F of Figures 4-6, ENPP1-, 2- and 3-immunoreactivities were detected in P2X2R-, P2X3Rand PAP-positive cells. Of the ENPP1-, 2and 3-positive ones, $87.1 \pm 7.6 \%, 82.9 \pm 9.1 \%$ and $77.8 \pm 10.5 \%$, respectively, were P2X2R-positive ones, and $83.9 \pm 11.5 \%$,
$93.1 \pm 11.4 \%$ and $82.6 \pm 10.0 \%$, respectively, were P2X3R-positive ones (Table 3). As for PAP-immunoreactivity in ENPP1-, 2- and 3-positive ones, $60.9 \pm 14.8 \%, 49.8 \pm 12.9 \%$ and $54.6 \pm 6.4 \%$, respectively, were PAPpositive ones (Table 3 ). In addition, we performed immunostaining for NT5E, as an adenosine-generating enzyme, but its immunoreactivity was hardly detectable in rat DRGs (data not shown). Based on these results, we judged that ENPP1, 2 and 3 were mainly expressed in small/medium-sized DRG neurons, which coexpressed P2X2R, P2X3R and PAP.

\section{Colocalization of ENT1 and PAP in rat DRGs}

In DRGs, adenosine generated by ectoenzymes through PAP activates adenosine A1R, inducing anti-nociceptive signaling, and then it has to be cleared by transporters such as ENT1. ${ }^{4,27}$ As shown in Figure 7, the PAP-positive DRG neurons exhibited immunoreactivity for ENT1. On quantification, $93.5 \pm 2.9 \%$ of the PAP-positive DRG neurons were ENT1-positive, whereas $44.3 \pm 13.2 \%$ of ENT1-positive ones were PAP-positive ( $v s \%$ of the PAPpositive ones, $\mathrm{P}<0.01$, paired $t$-test), they being colocalized in DRG neurons.

\section{Discussion}

The purpose of this study is to reveal the expression and localization of ENPPs in rat DRG. ENPP1, 2 and 3 were detected in small- and medium-sized DRG neurons, and were coexpressed in P2X2R, P2X3R and PAP-positive ones. Additionally, ENT1 was colocalized in PAP-positive DRG neurons. These results suggested that ENPP1, 2 and 3 play an important role in metabolism of extracellular ATP by cooperating with PAP and ENT1, contributing to extracellular adenosine clearance in small- and medium-sized DRG neurons. ATP acts as a neurotransmitter via homomeric $\mathrm{P} 2 \mathrm{X} 3 \mathrm{R}$ and heteromeric P2X2/3R in small-sized $\mathrm{C}$ - and medium-sized A $\delta$-fibers, respectively, ${ }^{24-26}$ and release of ATP from DRG neurons was increased in neuropathic pain after sciatic nerve injury in rats, ${ }^{28}$ suggesting that ectoenzymes are important for regulation of the extracellular ATP level involved in nociceptive signaling. In this study, ENPP1, 2 and 3 were found to be localized in smalland medium-sized DRG neurons, in which P2X2R and P2X3R were coexpressed. Stefan et al., in two studies of 1999 and 2006, reported that ENPP1, 2 and 3 could hydrolyze ATP to AMP. ${ }^{15,18}$ As clearance systems following this hydrolysis, PAP, which can hydrolyze AMP to adenosine, ${ }^{6}$ and ENT1, which can take up adenosine, ${ }^{29}$ were found to be coexpressed by DRG neurons. In contrast, NTPDase2 was also detected in DRG, but was expressed by satellite cells surrounding the soma of DRG neurons, as found by Braun et al. ${ }^{30}$ Although NTPDase2 hydrolyzes ATP to $\mathrm{ADP},{ }^{31-33}$ and then the generated ADP needs to be metabolized to AMP and/or adenosine sequentially, to our limited knowledge, there is no information on the metabolic system for ADP so far. Collectively, we suggest that the main clearance system for ATP is ENPPs-PAP-ENT1 in DRG neurons, especially small-sized ones, implying that

\section{ENT1}

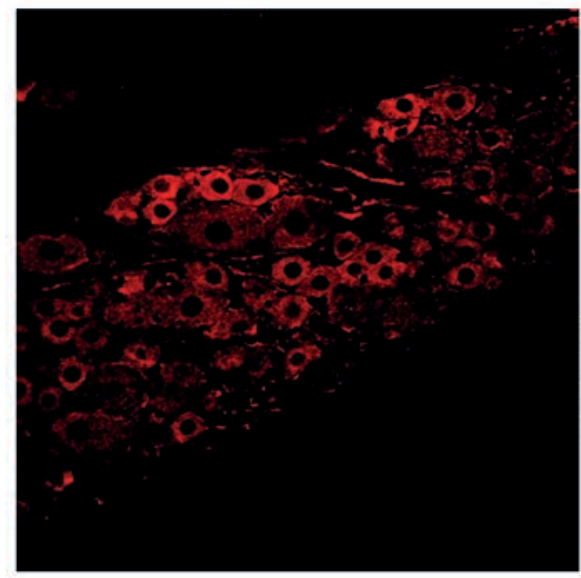

PAP

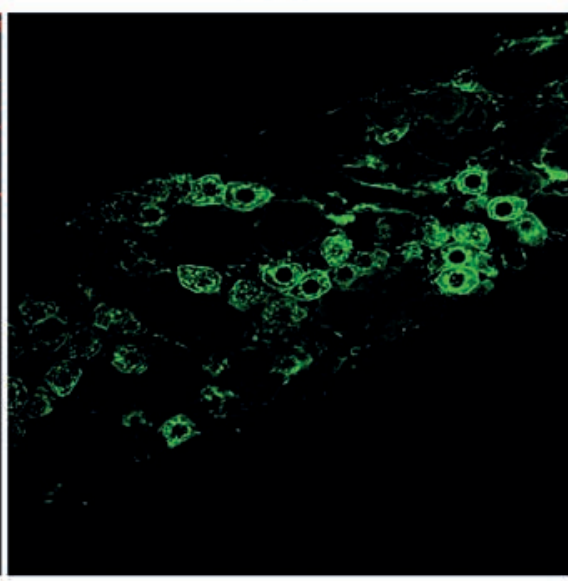

Merge

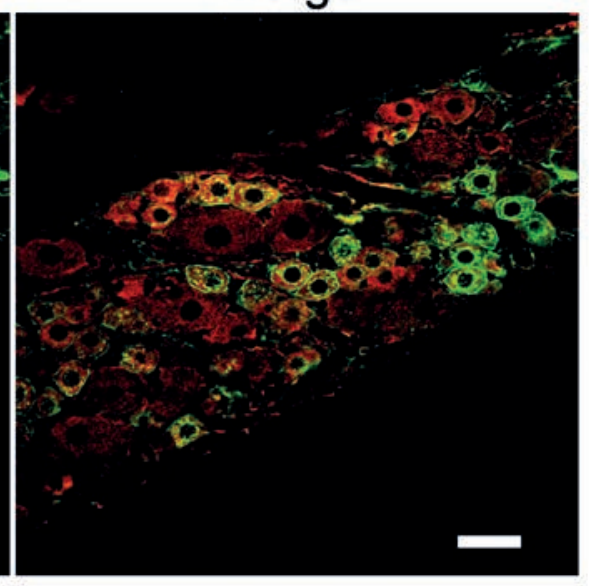

Figure 7. Immunohistochemical analysis of ENT1 and PAP in rat DRG. Double-immunostaining for ENT1 (red) and PAP (green) is shown. Representative images from four independent experiments are shown. Scale bar: $50 \mu \mathrm{m}$. 
this clearance system plays an important role in regulation of adenine nucleotide/nucleoside signaling. This is strongly supported by the findings that PAP-knockout mice showed increased nociceptive sensitivity in mouse inflammation and neuropathic pain models, and intrathecal administration of recombinant PAP to neuropathic pain models caused anti-nociception through activation of adenosine A1R via adenosine generation..$^{6,27}$ Therefore, harmonized regulation of ATPP2X2/3R signaling by the ENPPs-PAPENT1 cascade is considered to be critical for anti-nociceptive signaling.

The ENPP2-positive rate in all DRG neurons was almost the same as that in the case of ENPP1. Additionally, the mRNA expression level of ENPP2 was greater than those of ENPP1 and 3. ENPP2 is also known as autotaxin and is a secreted glycoprotein and can hydrolyze lysophosphatidylcholine to lysophosphatidic acid (LPA). ${ }^{34}$ Inoue et al. reported that LPA signaling via an LPA receptor (LPA1) is important for the initiation of neuropathic pain. ${ }^{35}$ Thus, there is the possibility that ENPP2 expression in DRG might contribute to initiation of nociceptive signaling via metabolism of lysophosphatidylcholine.

In this study, we suggest that ENPP1, 2 and 3 are involved in metabolism of extracellular ATP by small- and medium-sized DRG neurons, and the clearance system for adenine nucleotide/nucleoside consisted of ENPPs, PAP and ENT1 might be important for harmonized regulation of ATP-mediated nociceptive signaling and adenosine-mediated anti-nociceptive signaling in DRG.

\section{References}

1. Kanno T, Yaguchi T, Nishizaki $T$. Noradrenaline stimulates ATP release from DRG neurons by targeting beta(3) adrenoceptors as a factor of neuropathic pain. J Cell Physiol 2010;224:345-51.

2. Chen CC, Akopian AN, Sivilotti L, Colquhoun D, Burnstock G, Wood JN. A P2X purinoceptor expressed by a subset of sensory neurons. Nature 1995;377:428-31.

3. Lewis C, Neidhart S, Holy C, North RA, Buell G, Surprenant A. Coexpression of $\mathrm{P} 2 \mathrm{X} 2$ and $\mathrm{P} 2 \mathrm{X} 3$ receptor subunits can account for ATP-gated currents in sensory neurons. Nature 1995;377:432-5.

4. Governo RJ, Deuchars J, Baldwin SA, King AE. Localization of the NBMPRsensitive equilibrative nucleoside transporter, ENT1, in the rat dorsal root ganglion and lumbar spinal cord. Brain Res 2005;1059:129-38.
5. Zimmermann H, Zebisch M, Strater N. Cellular function and molecular structure of ecto-nucleotidases. Purinergic Signal 2012;8:437-502.

6. Zylka MJ, Sowa NA, Taylor-Blake B, Twomey MA, Herrala A, Voikar V, et al. Prostatic acid phosphatase is an ectonucleotidase and suppresses pain by generating adenosine. Neuron 2008;60: 111-22.

7. Sowa NA, Taylor-Blake B, Zylka MJ. Ecto-5'-nucleotidase (CD73) inhibits nociception by hydrolyzing AMP to adenosine in nociceptive circuits. J Neurosci 2010;30:2235-44.

8. Sawynok J. Adenosine and ATP receptors. Handb Exp Pharmacol 2007:30928

9. Kukulski F, Levesque SA, Sevigny J. Impact of ectoenzymes on $\mathrm{p} 2$ and $\mathrm{p} 1$ receptor signaling. Adv Pharmacol 2011;61:263-99.

10. Lavoie EG, Gulbransen BD, MartinSatue M, Aliagas E, Sharkey KA, Sevigny J. Ectonucleotidases in the digestive system: focus on NTPDase3 localization. Am J Physiol Gastrointest Liver Physiol 2011;300:G608-20.

11. Sevigny J, Sundberg C, Braun N, Guckelberger O, Csizmadia E, Qawi I, et al. Differential catalytic properties and vascular topography of murine nucleoside triphosphate diphosphohydrolase 1 (NTPDase1) and NTPDase2 have implications for thromboregulation. Blood 2002;99:2801-9.

12. Mizumoto N, Kumamoto T, Robson SC, Sevigny J, Matsue H, Enjyoji K, et al. CD39 is the dominant Langerhans cellassociated ecto-NTPDase: modulatory roles in inflammation and immune responsiveness. Nat Med 2002;8:358-65.

13. Vongtau HO, Lavoie EG, Sevigny J, Molliver DC. Distribution of ectonucleotidases in mouse sensory circuits suggests roles for nucleoside triphosphate diphosphohydrolase-3 in nociception and mechanoreception. Neuroscience 2011;193:387-98.

14. McCoy E, Street S, Taylor-Blake B, Yi J, Edwards M, Wightman M, et al. Deletion of ENTPD3 does not impair nucleotide hydrolysis in primary somatosensory neurons or spinal cord. F1000Res 2015;3:163.

15. Stefan C, Gijsbers R, Stalmans W, Bollen $M$. Differential regulation of the expression of nucleotide pyrophosphatases/ phosphodiesterases in rat liver. Biochim Biophys Acta 1999;1450:45-52.

16. Vekaria RM, Shirley DG, Sevigny J, Unwin RJ. Immunolocalization of ectonucleotidases along the rat nephron. Am J Physiol Renal Physiol 2006; 290:F550-60.
17. Scott LJ, Delautier D, Meerson NR, Trugnan G, Goding JW, Maurice M. Biochemical and molecular identification of distinct forms of alkaline phosphodiesterase I expressed on the apical and basolateral plasma membrane surfaces of rat hepatocytes. Hepatology 1997;25:995-1002.

18. Stefan C, Jansen S, Bollen M. Modulation of purinergic signaling by NPP-type ectophosphodiesterases. Purinergic Signal 2006;2:361-70.

19. Nishida K, Kitada T, Kato J, Dohi Y, Nagasawa K. Expression of equilibrative nucleoside transporter 1 in rat circumvallate papillae. Neurosci Lett 2013;533:104-8.

20. Bergman E, Ulfhake B. Loss of primary sensory neurons in the very old rat: neuron number estimates using the disector method and confocal optical sectioning. J Comp Neurol 1998;396:211-22.

21. Ishikawa T, Miyagi M, Ohtori S, Aoki $\mathrm{Y}$, Ozawa $\mathrm{T}$, Doya $\mathrm{H}$, et al. Characteristics of sensory DRG neurons innervating the lumbar facet joints in rats. Eur Spine J 2005;14:559-64.

22. Ruscheweyh R, Forsthuber L, Schoffnegger D, Sandkuhler J. Modification of classical neurochemical markers in identified primary afferent neurons with Abeta-, Adelta-, and C-fibers after chronic constriction injury in mice. J Comp Neurol 2007; 502:325-36.

23. Chao T, Pham K, Steward O, Gupta R. Chronic nerve compression injury induces a phenotypic switch of neurons within the dorsal root ganglia. J Comp Neurol 2008;506:180-93.

24. Cockayne DA, Hamilton SG, Zhu QM, Dunn PM, Zhong Y, Novakovic S, et al. Urinary bladder hyporeflexia and reduced pain-related behaviour in P2X3-deficient mice. Nature 2000; 407:1011-5.

25. Souslova V, Cesare P, Ding Y, Akopian AN, Stanfa L, Suzuki R, et al. Warmcoding deficits and aberrant inflammatory pain in mice lacking $\mathrm{P} 2 \mathrm{X} 3$ receptors. Nature 2000;407:1015-7.

26. Tsuda M, Koizumi S, Kita A, Shigemoto $\mathrm{Y}$, Ueno $\mathrm{S}$, Inoue $\mathrm{K}$. Mechanical allodynia caused by intraplantar injection of P2X receptor agonist in rats: involvement of heteromeric $\mathrm{P} 2 \mathrm{X} 2 / 3$ receptor signaling in capsaicininsensitive primary afferent neurons. $\mathrm{J}$ Neurosci. 2000;20:RC90.

27. Lee YW, Yaksh TL. Pharmacology of the spinal adenosine receptor which mediates the antiallodynic action of intrathecal adenosine agonists. J Pharmacol Exp Ther 1996;277:1642-8.

28. Matsuka $\mathrm{Y}$, Ono $\mathrm{T}$, Iwase $\mathrm{H}$, 
Mitrirattanakul S, Omoto KS, Cho T, et al. Altered ATP release and metabolism in dorsal root ganglia of neuropathic rats. Mol Pain 2008;4:66.

29. Nagasawa K, Kawasaki F, Tanaka A, Nagai K, Fujimoto S. Characterization of guanine and guanosine transport in primary cultured rat cortical astrocytes and neurons. Glia 2007;55:1397-404.

30. Braun N, Sevigny J, Robson SC, Hammer K, Hanani M, Zimmermann H. Association of the ecto-ATPase NTPDase2 with glial cells of the peripheral nervous system. Glia
2004;45:124-32.

31. Kegel B, Braun N, Heine P, Maliszewski CR, Zimmermann H. An ecto-ATPase and an ecto-ATP diphosphohydrolase are expressed in rat brain. Neuropharmacology $\quad$ 1997;36:1189. 200.

32. Kukulski F, Levesque SA, Lavoie EG, Lecka J, Bigonnesse F, Knowles AF, et al. Comparative hydrolysis of $\mathrm{P} 2$ receptor agonists by NTPDases 1, 2, 3 and 8 . Purinergic Signal 2005;1:193-204.

33. Mateo J, Harden TK, Boyer JL. Functional expression of a cDNA encoding a human ecto-ATPase. Br J Pharmacol 1999;128:396-402.

34. Umezu-Goto M, Kishi Y, Taira A, Hama K, Dohmae N, Takio K, et al. Autotaxin has lysophospholipase D activity leading to tumor cell growth and motility by lysophosphatidic acid production. J Cell Biol 2002;158:227-33.

35. Inoue M, Rashid MH, Fujita R, Contos JJ, Chun J, Ueda H. Initiation of neuropathic pain requires lysophosphatidic acid receptor signaling. Nat Med 2004; 10:712-8. 